\title{
O vazio e a "comunidade que vem": reflexões político-teológicas desde a pandemia da COVID-19
}

\section{Daniel Santos Souza*}

\section{Resumo}

Esse artigo tem a comunidade no contexto da pandemia da COVID-19 como um conceito organizador. Com os cenários de isolamento social, as perguntas pelo "viver junto" e o "viver só" tornam-se latentes. Para ensaiar possibilidades práticoteóricas para o problema do viver comum, organizei esse artigo a partir das seguintes temáticas: i) a aproximação entre a comunidade e o imaginário da trindade, com novas possibilidades de leitura a partir das noções de "makom" e de "pericórese"; ii) a reflexão sobre a "comunidade que vem" e as propostas de dessubjetivação e esvaziamento de uma noção ideal e colonial de humanidade; e iii) as leituras teológicas sobre a graça e as "brechas" possíveis para a constituição de arranjos éticos comuns. O movimento do texto, portanto, nos coloca diante do dilema da vida na pandemia e, nesse cenário de insegurança, ensaia estratégias imaginativas que assumem o vazio (de deus e do humano) para nos arriscarmos em uma (im)possibilidade da vida em relação.

Palavras-chave: pandemia; dessubjetivação; economia da graça; makom; desertar.

\section{The Void and "the Coming Community": Political- Theological Reflections since COVID-19 Pandemic}

\footnotetext{
Abstract

The paper has the community, in the context of the COVID-19 pandemic, as an concept. The social isolation rose the questions about "living together" and "living alone" becoming latent. To try these practical-theoretical possibilities about the problem of common living, I organized this article based on the following themes: i) the approximation between the community and the imaginary of the trinity, with new possibilities for reading from the notions of "makom" and "Perichoresis"; ii) the

* Universidade Federal do ABC. Doutor e Mestre em Ciências da Religião, licenciado em Filosofia e Bacharel em Teologia pela Universidade Metodista de São Paulo (UMESP). Atualmente, é Pesquisador Doutor Colaborador na Universidade Federal do ABC (UFABC), em uma investigação de pós-doutorado no Programa de Pós-Graduação em Filosofia. dan.vca@gmail.com .
} 
reflection on "The Coming Community" and the proposals for desubjectivation and emptying of an ideal and the colonial notion of humanity the reflection on "The Coming Community" following by the proposals for desubjectivation and emptying of an ideal as well as the colonial notion of humanity; and iii) theological readings about grace and possible "gaps" for the building of common ethical arrangements. The movement of the text, therefore, places us in the face of the dilemma of a life in the pandemic and, as a scenario of insecurity, rehearses rehearsing imaginative strategies assuming the void (of god and of the human) to risk ourselves in an (im)possibility of life in a relation.

Key-words: pandemic; desubjectivation; economy of grace; makom; desert.

\section{El vacío y la "comunidad que viene": reflexiones político- teológicas desde la pandemia del COVID-19}

\section{Resumen}

El artículo tiene la comunidad en el contexto de la pandemia COVID-19 como concepto organizativo. Con escenarios de aislamiento social, las preguntas sobre "vivir juntos" y "vivir solo" se vuelven latentes. Para probar las posibilidades práctico-teóricas del problema de la convivencia, organicé este artículo en base a los siguientes temas: i) la aproximación entre la comunidad y el imaginario de la trinidad, con nuevas posibilidades de lectura a partir de las nociones de "makom" y "Pericoresis"; ii) la reflexión sobre la "comunidad que viene" y las propuestas de desubjetivación y vaciamiento de una noción ideal y colonial de humanidad; y iii) lecturas teológicas sobre la gracia y posibles "lagunas" para la constitución de arreglos éticos comunes. El movimiento del texto, por tanto, nos coloca frente al dilema de la vida en la pandemia y, en este escenario de inseguridad, ensaya estrategias imaginativas que asumen el vacío (de dios y de humano) para arriesgarse en un (im) posibilidad de vida en relación.

Palabras llave: pandemia; desubjetivación; economía de gracia; makom; defecto.

"não há a comunidade, só há algo de comunidade, que circula"

(Revista Tiqqun)

\section{i. Introdução: uma vida na quarentena?}

Paul B. Preciado, na quarentena da COVID-19, narrou a sua experiência de ser infectado pelo vírus: "não tive dificuldade em respirar, mas era difícil acreditar que eu continuaria a respirar. Eu não tinha medo de morrer. Eu tinha medo de morrer sozinho" (PRECIADO, 2020a). A solidão aparece como mais uma marca de um vírus. A asfixia do corpo só. A vida no limite do deserto. Um espaço habitável por quem precisa ter a coragem de enfrentar os seus demônios - aquilo que cinde, que separa, quebra (diabolos). Inclusive o demônio como medo da morte. A cisão com o tempo-agora. Antes da 
aventura do viver junto em comunidade, a quarentena nos abriu a perspectiva, sempre presente, do viver só, mesmo entre outros. Um corpo dividido que precisa se sentir de outro modo. Não há mais o encontro carne-a-carne. Pele. Resta-nos corpos-virtuais. E a presença das palavras para se povoar o silêncio ${ }^{1}$. Uma ideia provisória de morada coletiva.

Se é no limiar da vida que se pode encontrar e criar possibilidades de uma vida, de "formas-de-vida", é talvez, aqui, que se possa imaginar algo. Ou simplesmente, aqui, que se possa assumir o colapso de uma subjetividade que não sabe dizer seu mundo. Nesse espaço, podemos redimir o silêncio da sua tarefa produtiva, da sua obrigação de espera pela palavra, pelo ofício, pelo dever ser, por um dizer urgente e operativo. Vilém Flusser afirma que "a separação entre intelecto e língua, entre o aspecto subjetivo e objetivo da realidade, portanto, quebra a realidade. $\mathrm{O}$ intelecto supera a língua e dissolve-se. O resto é silêncio". (FLUSSER, 2007, p. 159). Estamos no abismo do indizível. O que podemos dizer de nós, do mundo que está ruindo, das "formas-de-vida" ensaiadas em casa? Estamos no colapso da língua e de um mundo produtivo ${ }^{2}$. Ainda com Vilém Flusser: "a explicação da conversação é lógica, a explicação da oração é mítica” (2007, p. 159). A quarentena parece nos empurrar para o terreno da "oração", o nada-dizer. O estar para além da língua. O ruir da palavra. Nesse cenário parece que adentramos em um campo propriamente mítico/ficcional. Não que a lógica não tenha também a sua ficção. No mítico, o fim do mundo encontra o seu espaço. E também a possibilidade privilegiada de ficcionar subjetividades vindouras. Um corpo qualquer, um mundo qualquer, uma subjetividade qualquer - como aprendi com o filósofo Giorgio Agamben (2013). Destituir a palavra. Ter a coragem do deserto. O vazio. Uma saída no cenário da regulação da vida pelas políticas de segurança e de trabalho? São gestos no silêncio. Como escreveu Franco [Bifo] Berardi: "não há pânico, nem medo, mas silêncio. Rebelar-se revelou-se inútil; então, apenas paremos" (BERARDI, 2020). Parar a vida. Ou parar um modo de vida.

Paul B. Preciado faz a pergunta necessária no cenário de pandemia e quarentena: "sob que condições e de que forma valeria a pena viver a

As reflexões sobre o silêncio e a quarentena foram explicitadas por mim no artigo para a Revista Senso: a redenção do silêncio, publicado em 04 de abril de 2020. Disponível em: https://url.gratis/icjCP.

2 Em relação aos modos produtivos e as vinculações de trabalho no cenário da pandemia, é importante apontar as mobilizações de entregadoras e entregadores de aplicativos. Há greves e paralisações acontecendo para a denúncia da relações trabalhistas e a precarização da vida. Para saber mais, acesse essa matéria da Ponte jornalismo: https://url.gratis/xpCtk. 
vida?" (PRECIADO, 2020b). Sobre essa provocação, me interessa uma obra da artista Ananda Trezena (2020): "enquanto isso tudo não acaba" ${ }^{3}$. Como ela escreve na apresentação: "enquanto isso tudo não acaba é uma rede de compartilhamento online de propostas de encontro durante o período de isolamento social" (TREZENA, 2020). A plataforma utilizada "sugere o envio de propostas anônimas, reunindo sugestões, perspectivas e desafogos acerca das possibilidades e impossibilidades de encontro em tempos de quarentena" (TREZENA, 2020). Entre as respostas, encontrei possibilidades interessantes: "aos que podem, recomendo um brinde de vinho com a avô pela câmera"; "dormir junto no zoom"; "telefone de latinha com o vizinho"; "imaginar o toque"; "dançar junto a mesma música pela câmera"; "cantar parabéns na fila do supermercado"; "gozar meu corpo e mente como gozava a vida antes"; "gritar bem alto da janela e esperar um retorno". Muitas das respostas indicadas no trabalho abrem as questões sobre o viver junto e o viver só. "enquanto isso tudo não acaba" faz a pergunta pela vida no tempo-agora. A indagação primordial é sobre qual vida e qual tempo podemos viver - nos desbloqueios de uma imaginação que sabe se aventurar para além das armadilhas do vírus.

As reflexões postas até aqui nos colocam diante das problemáticas sobre a comunidade. Por isso, me aproximo de Martin Buber, que - em toda a sua obra e especialmente na série de Conferências Sobre comunidade (2012) - deseja compreender a transformação da vida social. Há um interesse pela "vida em comum", em que a condição relacional e o princípio dialógico sejam determinantes para além de toda "coisificação" do outro e do mundo. O seu interesse não é, apenas, elaborar uma reflexão teórica e conceitual. Há um desejo por uma concretude do evento-vida. Por isso, a dimensão ética é o elemento fundante: como habitamos o mundo? Essa pergunta é anterior a qualquer outra. Para Newton A. von Zuben, em M. Buber há um amadurecimento do problema antropológico que se deve a dois fatores: "a decomposição de antigas formas orgânicas de convivência direta entre homens" (sic), como família, comuna aldeã ou urbana, companheirismo; e "o agravamento da solidão

3 Essa obra integra a $397 f$ fix, que "foi criado para reunir trabalhos de um grupo de 13 artistas que conviveram, sobretudo virtualmente, nesses primeiros meses do ano de 2020 no programa Clínica Geral, do Ateliê397. Essa não-exposição - pois o 397flix é uma plataforma e não uma exposição virtual - apresenta trabalhos novos, concebidos num período em que as galerias e museus estão fechados. Tal como a plataforma streaming que ele emula, o 397 flix acolhe tudo: de Hollywood aos independentes, de documentários críticos a filmes de ação, deixando com o público a tarefa de fazer suas escolhas e percursos” (RIVITTI, 2020). A obra está disponível em: https://url.gratis/4F2ve. 
do homem" (sic), um ser humano que perdeu o "sentimento de habitar" o universo, que perdeu o "estar-em-casa", "uma segurança sociológica que o preservara do sentimento de abandono total" (ZUBEN, 2012, p. 130). Se o modo de vida esperado em uma sociedade neoliberal (HAN, 2017; DARDOT \& LAVAL, 2016) é baseado na separação e no esgotamento, uma "sociedade do desempenho" formada na lógica do "sujeito-empresa", "empreendedor de si", M. Buber nos provoca para a responsabilidade de um "agir em comum", para além da "sociedade de interesses". Uma saída: viver "entre-dois". Esse redescobrir o comum não nos coloca nem no "individualismo atomístico", nem no "coletivismo totalitário". A comunidade de que fala Buber, é uma "comunidade orgânica", uma "comunidade de comunidades". No entanto, como viver em comunidade no isolamento da quarentena, "enquanto tudo isso não acaba"? Como esse contexto nos faz dizer o mundo desde as linguagens mítico-simbólicas que permeiam vivências de espiritualidade?

Se o viver comum é um problema central nessa reflexão, organizo esse artigo a partir das seguintes temáticas: i) a aproximação entre a comunidade e o imaginário da trindade, com novas possibilidades de leitura a partir das noções de "makom" e de "pericórese"; ii) a reflexão sobre a "comunidade que vem" e as propostas de dessubjetivação e esvaziamento de uma noção ideal e colonial de humanidade; e iii) as leituras teológicas sobre a graça e as "brechas" possíveis para a constituição de arranjos éticos comuns. O movimento do texto, portanto, nos coloca diante do dilema da vida na pandemia e, nesse cenário de insegurança, ensaia estratégias imaginativas que assumam o vazio (de teus e do humano) para nos arriscarmos em uma (im) possibilidade da vida em relação.

\section{ii. Aetrs-vazio 4 e o desejo para se viver o comum}

Para essa problemática, há uma intuição no teólogo Jurgen Moltmann que me interessa. Em um texto-síntese do seu pensamento teológico, ele escreve: "Deus não é somente uma pessoa com a qual podemos falar, mas também o espaço no qual podemos desenvolver nossas vidas. Segundo a tradição judaica, um dos nomes de Deus é Makom (espaço)" (MOLTMANN, 2008, p. 15). Essa afirmação de Moltmann tem relação com uma fala de Paulo em Atos 17.28: "pois nele vivemos, nos movemos e existimos". teus é visto

\footnotetext{
Tento, nesse artigo, brincar com a língua, rasurar as palavras para usá-las de outros modos. Um exercício de dessacralização ou profanação da língua e das palavras-com-poder. Nesse caso, faço esse jogo com deurs.
} 
como uma habitação possível, um espaço de liberdade. Há uma brecha no pensamento desse teólogo alemão - relacionada aos discursos paulinos - que quero ocupar. Diz Moltmann: “o amor dá espaço e tempo para a liberdade. Onde quer que nós experimentemos este espaço livre, aí nós experimentamos a presença de Deus entre nós" (2008, p. 15). E se pensarmos o espaço como esse vazio? Um espaço feito lugar por meio de nossos jogos e interações. Ocupar deus. Ou fazê-lo acontecer como vazio diante da destituição e da "barricada de amor vivo". Não mais a entidade soberana, não mais o absoluto, mas um espaço de liberdade para se viver a potência de nossos corpos e encontros. Mas esse espaço não pode ser confundido com a formação de um novo "povo" identitário em Deus, nos moldes do "paradigma do êxodo" 5.

Se retomarmos a noção de pericórese presente em Moltmann, temos uma "intersubjetividade triádica" marcada pelo "movimento e tranquilidade", um "descanso mútuo" e uma "dança circular" (2008, p. 89-90). A pericórese tem um sentido, desde o mundo da igreja grega, de "inabitação mútua", "uma comunhão sem uniformidade e uma personalidade sem individualismo" (MOLTMANN, 2008, p. 88). Como substantivo, pericórese "designa volta ou rotação; o verbo indica um movimento de um para o outro, algo como alcançar ao redor e caminhar ao redor, circundar, abraçar" (2008, p. 88). Há, portanto, a possibilidade de se compreender a trindade como uma “comunidade não-hierárquica". Na pericórese as pessoas trinitárias são "simultaneamente pessoas e espaço de movimento", em uma trindade sempre aberta e convidativa (MOLTMANN, 2008, p. 90-91). Uma inoperosidade relacionada a um deslocamento, um dançar que é movimento em direção à vivência de liberdade. Nela, cada "pessoa existe (ek-siste) além de em si também nas outras duas. É o poder do pleno amor que faz com que cada pessoa saia de si mesma e esteja completamente presente na outra" (2008, p. 90). Podemos "torcer" ainda mais esse conceito se nos aproximamos da reflexão de Ivone Gebara: “trindade é uma palavra sobre nós mesmos, sobre aquilo que conhecemos, sobre aquilo que experimentamos em nossa carne, em nossa história" (GEBARA, 1994, p. 27).

\footnotetext{
Muitas das reflexões desse texto foram ensaiadas em minha tese de doutorado, defendida em 2019, especialmente o seu capítulo 7. O título do texto: "A 'revolta da ineficiência': os acontecimentos de junho de 2013 no Brasil e suas destituições político-teológicas". Existe aí instrumentais teóricos que podem nos ajudar nos exercícios reflexivos do nosso tempo-agora, como também foram utilizados para ver “junho”. Para acessá-lo: https:// url.gratis/4c1DC.
} 
De um lado temos um teus vazio, um espaço para ser habitado; do outro, temos a compreensão que nós somos esse espaço de possibilidade. As leituras de Jurgen Moltmann e Ivone Gebara nos favorecem em um exercício de nomadismo e "destituição" de uma determinada imagem trinitária. Não é simples assumir teus (e o "sujeito") como makom (espaço). É, portanto, o "qualquer... que se queira" - como ensaiou o filósofo Giorgio Agamben enquanto possibilidade aberta no movimento em direção a outros lugares e "diferenciações de si". Ao olharmos com detalhe o termo qualquer, temos múltiplas possibilidades de interpretação. Em uma "nota da tradução" referente a essa palavra, vê-se que no texto original em italiano, o termo é dito de modos distintos qualunque e qualsivoglia (AGAMBEN, 2013, p. 9). O qualunque (qualquer) é qual-si-voglia (qual-se-queira). Em português, o pronome "qualquer" tem uma estrutura morfológica semelhante ao italiano qual-si-voglia: "qual + quer". Interesso-me por essa definição: um "qualquer... que se queira", que "contém sempre uma referência ao desejar (libet), o ser qual-se-queira está em relação original com o desejo" (AGAMBEN, 2013, p. 10). Voltamos ao espaço da "pura potência" em que a singularidade é uma "singularidade qualquer". Não na ideia de um singular diante de um "universal” como uma propriedade comum (ser francês, ser muçulmano). Desse modo, como "pura potência", "o ser-qual é recuperado do seu ter esta ou aquela propriedade, que identifica o seu pertencimento a este ou aquele conjunto, a esta ou aquela classe" (AGAMBEN, 2013, p. 10). Recupera-se o "ser-qual" para o seu próprio pertencimento, para ser "qual-se-queira". É a pura possibilidade.

O qualquer é o esvaziamento como toda possibilidade de poder e podernão. Recordo-me de um curso com Peter Pál Pelbart ${ }^{6}$ - "tempo e criação". $\mathrm{Na}$ primeira aula, ele apresentou alguns mitos cosmogônicos. Um me chamou a atenção. Ele vem do Talmud. Para criar o mundo, Deus precisou dar espaço para que o mundo aparecesse, precisou se retrair, refluir. O gesto de criação tem mais relação com o desaparecimento do que com o comando e a ordem. Esse criar não é uma omissão. É retração - com a importância do silêncio. Deus tem a coragem de sumir, de destituir-se para que outra coisa seja possível. É a retomada da "impotência como potência". Se assim for, a "comunidade trinitária" seria um "espaço" vazio, uma comunidade que não é como substância. O espaço evoca o uso e o jogo. Ao falarmos assim, falamos

6 Peter Pál Pelbart foi o professor de um curso - promovido pelo Colégio São Domingos, em 2019/2020 - para professoras e professores da escola. Um processo de reflexão permanente. O tema: "tempo e criação". 
em nos deixar afetar e nos deixar arrastar pelos "fluxos" de um mundo. Uma possibilidade de mostrar-nos como um lugar para acontecimentos inesperados. Não um cogito nos moldes "modernos", mas um vazio - ou um aberto. Estamos na insegurança, inclusive da ciência. Não é essa também uma brecha aberta no cenário de pandemia sobre o futuro, a vida e a existência?

Para essa temática, ainda preciso trazer para esse diálogo um trecho da publicação da revista tiqqun ': "cada corpo é afetado por sua forma-devida como por um clinâmen, uma inclinação, uma atração, um gosto. Aquilo em direção ao qual se inclina um corpo inclina-se também, por sua vez, em direção a ele" (TIQQUN, 2019, p. 15). Um corpo afetado, inclinado e em relação. Nessa mesma lógica, a "forma-de-vida não se relaciona ao que eu sou, mas ao como eu sou aquilo que eu sou", como um "ser-em-situação" (2019, p. 18). É assumir o corpo como elo e como um espaço de "contaminação" - não a do vírus que causa a COVID-19. Como estabelecer possibilidades de "contaminação" que não sejam essas que nos assombram e sufocam a garganta e o peito? Como escreve Peter Pál Pelbart, "nem fusão, nem dialética intersubjetiva, nem metafísica da alteridade, mas solidão, ressonância, síntese disjuntiva, jogo polifônico" (PELBERT, 2008, p. 275). A nossa carne qualquer como makom, como a "persistência de um corpo em se deixar afetar, a despeito da verdade das situações que ele atravessa, por uma única forma-de-vida é função de sua rachadura" (TIQQUN, 2019, p. 22). E nessas brechas nos corpos (mesmo que borrados), é possível crescer "a ausência no mundo e a penúria das inclinações” (TIQQUN, 2019, p. 22). Em tempos pandêmicos, é inclinar-nos na virtualidade dos corpos que desejam ainda viver e estabelecer mundos comuns - na insegurança dos encontros e nas pequenas brechas cotidianas. Deixar-se sumir, desaparecer, retrair, para ser espaço aberto para que novas possibilidades de vida ainda sejam possíveis.

\section{iii. A (im)possibilidade de uma "comunidade que vem"}

No cenário de pandemia, muitas perguntas sobre o "que vem" aparecem. Quero me aproximar dessas intenções, mas de outro modo. Giorgio Agamben escreve um livro que nos ajuda nesses diálogos: A comunidade que vem (2013) ${ }^{8}$.

\footnotetext{
A Revista filosófica francesa Tiqqun - fundada em 1999 e encerrada em 2001 - tinha como objetivo "recriar as condições de uma outra comunidade" (AGAMBEN, 2013, p. 101). O termo vem do hebraico - Tikkun olam -, "frequentemente usado nas tradições cabalísticas e messiânicas, que indica simultaneamente reparação, restituição e redenção” (AGAMBEN, 2013, p. 101).

$8 \quad$ No texto Teología y lenguaje: del poder de Dios al juego de los niños (2012, p. 13-23), em uma
} 
Para a estranheza, o "que vem", aqui, não nos representa o futuro. É um "que vem" não-linear, não esperado como o dia seguinte da história. Estamos numa certa suspensão da exigência do factual, da relação estanque entre sujeito e objeto. A busca pela potência parece habitar o vazio entre as bipolaridades como "experiência antiga" e "experiência utópica". Peter Pál Pelbart entende que Agamben - nessa noção - tenha "colhido" um efeito de uma "mutação subjetiva no plano político" (PELBART, 2008, p. 273), uma "subjetividade mais esquizo, fluxionária, de vizinhança e ressonância, de distâncias e encontros, mais do que de vinculação e pertinência" (PELBART, 2008, p. 272-273). Em A comunidade que vem, Agamben "evoca uma resistência vinda, não como antes, de uma classe, um partido, um sindicato, um grupo, uma minoria; mas de uma singularidade qualquer, do qualquer um" (PELBART, 2008, p. 273). Como imaginar uma comunidade nessa singularidade qualquer sem cair na armadilha da sujeição e "filiação a uma identidade específica"? Nas reflexões de tiqqun", temos a "experiência da comunidade" quando "dois corpos afetados, em certo lugar e momento, pela mesma forma-de-vida acabam por se encontrar, eles fazem a experiência de um pacto objetivo, anterior a toda decisão" (TIQQUN, 2019, p. 30). O saber jogar com o "qualquer um" e o "ser ninguém" diante do medo do morrer. De algum modo, assumir a performance de desaparecer, deixar ir um modo de vida, de humano.

Uma experiência que não nos coloca no "fantasma metafísico" da "comunidade humana". Como pergunta Ailton Krenak em seu texto Ideias para adiar o fim do mundo: "somos mesmo uma humanidade?". De maneira mais direta, ele indaga: "por que insistimos tanto e durante tanto tempo em participar desse clube, que na maioria das vezes só limita a nossa capacidade de invenção, criatividade, existência e liberdade?" (KRENAK, 2019, p. 13). O arranjo colonial, fundado no imaginário do um, de uma totalidade, cria uma ideia de humano e de sub-humanos, desde uma hierarquia e racialização da vida.

conferência sobre Bataille (1986), Giorgio Agamben ainda faz um diálogo com dois textos importantes sobre a compreensão de comunidade: A comunidade inconfessável (1983), de Maurice Blanchot; e A comunidade inoperada (1986), de Jean-Luc Nancy. É importante ter isso no horizonte quando se compreende que o texto de Agamben, $A$ comunidade que vem está em diálogo com esses modos de pensar.

9 Tiqqun foi revista filosófica francesa, fundada em 1999 e encerrada em 2001, que tinha como objetivo "recriar as condições de uma outra comunidade" (AGAMBEN, 2013, p. 101). O termo vem do hebraico - Tikkun olam -, "frequentemente usado nas tradições cabalísticas e messiânicas, que indica simultaneamente reparação, restituição e redenção" (AGAMBEN, 2013, p. 101). 
Corpos dignos e indignos em um sistema de sexo/gênero, em territorializações do mundo. Uma invenção de um nós-humanos deslocados da terra, uma "abstração civilizatória" que "suprime a diversidade, nega a pluralidade das formas de vida, de existência e de hábitos. Oferece o mesmo cardápio, o mesmo figurino e, se possível, a mesma língua para todo mundo" (KRENAK, 2019, p. 22-23). A ruína dessa humanidade parece assustar. Mas de qual humanidade? Por isso, ainda, me interessa ainda as reflexões de Krenak:

por que nos causa desconforto a sensação de estar caindo? A gente não fez outra coisa nos últimos tempos senão despencar. Cair, cair, cair. Então, por que estamos grilados agora com a queda? Vamos aproveitar toda a nossa capacidade crítica e criativa para construir paraquedas coloridos. Vamos pensar no espaço não como um lugar confinado, mas como o cosmos onde a gente pode despencar com paraquedas coloridos. Há centenas de narrativas de povos que estão vivos, contam histórias, cantam, viajam, conversam e nos ensinam mais do que aprendemos nessa humanidade. Nós não somos as únicas pessoas interessantes no mundo, somos parte do todo. Isso talvez tire um pouco da vaidade dessa humanidade que nós pensamos ser, além de diminuir a falta de reverência que temos o tempo todo com as outras companhias que fazem essa viagem cósmica com a gente (KRENAK, 2019, p. 30-31).

Aprender a cair, a colocar um mundo em ruínas. Fazer desse terreno uma possibilidade de existência não mais centrada numa invenção de humano universalizado desde um "modelo" hierárquico e binário. O fim de um modo de vida nos desafia - desde espectros simbólicos/teológicos a imaginar outras possibilidades de viver comum. Não apenas pela realidade posta em um cenário de tecnopolitica que parece abarcar toda a vida, em realidades de trabalho e de construção de afetos por meio de espaços virtuais/digitais. Sabemos que nos atuais exercícios de "teletrabalho", temos "novas formas de medir, qualificar, avaliar - uma nova cidadania do desempenho que também é uma cidadania policial e gerencial: todos vigiam, todos denunciam, todos avaliam os 'serviços' e dão sua nota, todos participam e se sentem convocados em "fazer sua parte" (LZC, 2020a). É importante compreendermos esses arranjos pandêmicos para além do exercício de um futuro orientado por uma noção de progresso e de técnica que nos empurra sem suspeitas para um mundo "pós-humano", mas sem colocar em ruínas o pressuposto primeiro de uma lógica do "antropoceno" que ainda teima em conduzir nossas 
combinações políticas ${ }^{10}$. Neste ponto, interessa-me o projeto de investigação proposto por um grupo de pesquisadoras(es) diante da realidade pandêmica. O grupo com o nome Laboratório Zona de Contágio tem como problemas e estratégias de luta para vivências do comum:

1) Regimes de conhecimento (as disputas em relação à ciência, os saberes menores e não autorizados, as ontoepistemologias dos saberes das lutas, corpos como sensores); 2) Regimes de poder que atualizam formas de controle; Biopoder-Biopolítica, dispositivos (novas formas de mobilização e desempenho, tecnologias de gênero e racializadoras/racistas, a relação entre a casa, o corpo, o prazer e a produção); 3) Regimes tecnopolíticos e tecnoestéticos (a complexidade tecnosomática; dataficação, algoritmização da vida e novos modos de extração e trabalho; alteração nos modos de associação, desejos e individuações tecnomediadas); 4) Transição societal e os limites do capitaloceno/plantationoceno/antropoceno (terra e o mundo vivo, relação entre viventes; extrativismo ampliado e formas cosmopolíticas de luta) (LAB ZONA DE CONTÁGIO, 2020a).

O programa aqui posto não é uma tarefa simples e um exercício individual, mas um arranjo de possibilidades e "camaradagens" práticoteóricas. A pergunta é: como a teologia e as ciências da religião se deparam com as problemáticas aqui indicadas? A tarefa que tenho nesse artigo é modesta diante da provocação que temos. Há apenas lampejos e rastros para se colocar deus, o humano e uma determinada noção de comunidade em ruínas. Para isso, existem os rastros de nova produção de conhecimento, com modos de escancarar regimes de poder (sustentadas também em imaginários de teus), a necessidade em lidar com novas existências em ambientes virtuais "algorimizados" e a estratégia de se colocar na ruptura, na transição, na indicação rizomática de novas aberturas e novas conexões para uma "comunidade que vem". Encontrei uma provocação da Revista tiqqun que me parece importante para esse diálogo: não "há a comunidade, só há algo de comunidade, que circula" (TIQQUN, 2019, p. 32). Sem as perspectivas metafísicas e essencialistas de viver o comum, pensemos nos rastros de comunidade, como arranjo provisório, incerto, inseguro. Há "algo de comunidade" na pandemia, com afetos e inclinações que circulam, empurram, deslocam. Na comunidade de "cada forma-de-vida, entram

10 Sobre essa discussão, confira o texto de Ana Ester: "Teologia Biônica - contágios póshumanos decoloniais" (2020), lançado na Série Contágios Infernais, coordenada por Fellipe dos Anjos e João Luiz Moura, pela Editora Recriar. 
também comunidades de coisas e de gestos, comunidades de hábitos e de afetos, uma comunidade de pensamentos" (TIQQUN, 2019, p. 33).

Comunidade em "ato e potência", nos fluxos e atravessamentos em cada virtualidade de nossos encontros, e também "puramente em potência", como no exemplo de Bloom e sua comunidade que "não há" (TIQQUN, 2019, p. 35). Em detalhes, Bloom é uma figura central na revista tiqqun, inspirado no personagem de Joyce, ele "seria um tipo humano recémaparecido no planeta e que designa essas experiências brancas, presenças indiferentes, sem espessura, o homem ordinário" (PELBART, 2008, p. 269). Bloom é a "morte do sujeito e de seu mundo", por isso pode acontecer como "estranheza e inoperância", uma singularidade nebulosa, incerta, potente como possibilidades abertas de "subjetividades parciais". Bloom recoloca as subjetividades diante da potência passiva, "esvaziadas, prontas para tudo, que podem se difundir por toda parte, mas permanecem inalcançáveis, sem identidade mas reidentificáveis a todo instante" (AGAMBEN, 2016, p. 17). Os hábitos na pandemia podem ser irrupções que nunca se esgotam na própria prática, pois seguem sempre como o que vem. Irrupções de criação de um determinado comum, não como povo, pertencimento, mas como possibilidade de viver em um "meio que nos é hostil", com o medo da morte e ao mesmo tempo com uma força-fraca vendo - muitas vezes sozinhos - o morrer de um mundo, de um tipo de vida, de alguns modos de relação, de uma ideia de humano e de teus. E aqui saber fazer nascer novos começos e possibilidades.

\section{iv. O comum e a graça: arranjos relacionais na dessubjetivação}

Para essa temática, desejo incluir uma outra noção relevante: a graça. Joerg Rieger, em seu livro Graça sob pressão (2012), nos faz refletir sobre uma "economia da graça alternativa". Desde uma teologia wesleyana, ele pensa o legado da esperança cristã, uma "nova criação". Ele escreve: essa "nova criação" "é movida não por ortopráxis (ativismo social ou serviço) nem por ortodoxia (conhecimento teológico sobre como se amarrar à graça de um jeito que nos permite explorá-la como uma mercadoria)" (RIEGER, 2012, p. 57). Para além da "prática correta" ou da "crença correta", "uma relação com uma fonte de energia alternativa que cria uma economia da graça alternativa" (RIEGER, 2012, p. 57). Graça aqui é uma experiência de relação, "algo que acontece em nossa relação com Deus - uma relação que é iniciada por Deus e que convida a nossa resposta. Não existe uma 'substância' ou 'essência' da 
graça que exista à parte do relacionamento" (RIEGER, 2012, p. 59). Nessa relação entre Deus e nós, uma divindade que não poderá ser "comodificada" surge essa "energia". Há ainda nessa leitura uma marca da transcendência. Ele escreve: "a forma com que nos relacionamos com outras pessoas é indicativa da forma que nos relacionamos com Deus" (RIEGER, 2012, p. 61). A teologia e a relação com os imaginários de Deus apontam para a nossa vida cotidiana. São discursos desde nossas formas e modos de viver, como ele diz em outro momento: "entender a graça como relação nos desafia a construir relacionamentos de formas distintas" (RIEGER, 2012, p. 62) ${ }^{11}$.

Para a discussão que faço aqui, essa lógica me serve para pensar "linhas de fuga" aos problemas da exaustão de uma vida pandêmica orientada pela eficiência do trabalho e do controle tecnopolítico. A "nova criação" - dirá Rieger - é "sobre relacionamento e não posse". E essa perspectiva relacional que cria espaço para "uma economia da graça alternativa", colocando-nos para além da "exaustão": a "ilusão de que temos que tomar as coisas em nossas próprias mãos e que precisamos estar no controle de tudo"; e nos coloca além de uma ideia do cristianismo histórico e do "livre-mercado" de que "nosso conhecimento dos macetes e fontes corretas pode nos ajudar a explorar a 'graça gratuita" (RIEGER, 2012, p. 60), em uma relação de manutenção dos escolhidos para o controle. Busca-se, então, outras "formas-de-vida", com a criação de pequenos espaços do viver comum, em que a graça pode acontecer. Mas essa dinâmica que nos empurra a outros modos de existência não é algo exclusivo do "tempo-agora". Como nos provoca o Laboratório Zona de Contágio, "a crise de presença e a erosão das formas de vida em comum que agora sentimos de maneira radical é apenas um sintoma mais agudo de um modo de vida neoliberal que já vivíamos" (LAB ZONA DE CONTÁGIO, 2020a).

Imaginar, portanto, novas estratégias de subjetivação no terreno virtual, tecnomediado, também é uma tarefa teológica. Dentre tantas possibilidades,

11 Na teologia da libertação, há uma relação com a trindade e a comunidade. No livro Cristologia na encruzilhada, abordo essa questão: "De início, é importante salientar que a relação entre trindade e sociedade é algo muito presente nas teologias latino-americanas da libertação. A relação trinitária é o modelo da sociedade desejada. A partir desta comunhão não hierárquica, projetamos as relações sociais em que queremos viver. Esta noção é sistematizada por alguns teólogos, como Leonardo Boff, que interpreta a comunidade do Pai, Filho e Espírito Santo como protótipo da comunidade humana; e Juan Luis Segundo, que pensa a imagem do Deus-sociedade como a matriz para as nossas relações sociais. A trindade é, pois, o modelo para se construir o reino de Deus, a utopia da sociedade justa, liberta de pobrezas e intolerâncias, uma nova ordem social e cósmica a partir da comunhão divina que acontece parcialmente na história rumo a sua plenitude" (SOUZA, 2016, p. 154). 
minhas intuições partem da teologia da graça. Há algo de gratuidade nas virtualidades da quarentena, uma graça na irrupção, na incerteza e insegurança vinculadas a uma presença-ausente que nos colocam para viver uma vida, "além de uma sacralidade" (sacer) que conhecemos, uma vida para ser vivida no tempo que resta (DICKINSON, 2011, p. 175). Falamos de uma graça que não espera retorno. Para além de qualquer identidade que se coloque como um espaço fixo de pertencimento e segurança. Se uma marca teológica fundamental é a capacidade de ficcionar subjetividades e arranjos de vida, não estaríamos aqui em um desafio semelhante para ensaiar afetos - mesmo nos dilemas de vida desigual e capturada pela combinações necropolíticas entre estado e capitalismo neoliberal? Saber parar a vida pode ser uma boa provocação. São experimentos provisórios, tendas pelo deserto da virtualidade, com novas e outras dinâmicas de relação com os outros, com a terra, conosco.

Nessa mesma linha de graça e relação, posso ainda me aproximar da interpretação que Ivone Gebara realizará da ressureição de Cristo. Em sua leitura, Gebara pensará uma "tradição crística”, em que somos "Cristo umas para as outras". Na linguagem que tenho utilizado, talvez poderíamos pensar em um cristo qualquer (Giorgio Agamben). Desse modo, "Cristo é mais do que Jesus de Nazaré. Somos, cada um e cada uma de nós, Cristo ou da tradição crística" (2017, p. 108). Nessa perspectiva, que Jesus também participou, "ressuscitamos no cotidiano e ajudamos a ressuscitar no cotidiano" (GEBARA, 2017, p. 108). Se colocar em um movimento de um cristo qualquer pode nos levar para "inclinações" que gerem a energia da graça. Nessa lógica, também podemos buscar as interpretações que Luiza Tomita fará de Rita Nakashima Brock, especialmente a sua noção de Cristo como "crista/ comunidade", para além do "salvador-herói". Aqui poderíamos entender tanto o cristianismo ou uma vida pandêmica sem salvadores. A crista/comunidade "é uma realidade vivida, expressa em imagens relacionais, onde o heart se manifesta. Heart - o ser em estado de graça original - é o nosso guia aos territórios do poder erótico" (TOMITA, 2005, p. 111-112). Eros aqui pode ser assumido como um momento de irrupção de tudo "o que estava no íntimo" (Tatiana Roque), aproximando-se de toda "a capacidade de apaixonar-se" (Manuel Moyano). Corpos inclinados, elos, redes, afetos - alegres ou tristes. Nas relações para fora do "sujeito soberano" temos a possibilidade da graça, numa "política extática. Seu propósito não é resgatar a presença humana em dissolução de modo abstrato, a golpes de re/presentações, mas elaborar magias participáveis, técnicas de habitação não tanto de um território, mas de um mundo" (TIQQUN, 2019, p. 188-189). 
Mas essas mesmas irrupções podem também nos colocar em entrechoques, em colisões. Relembremos, por exemplo, a ambiguidade da palavra hostil. Por hostilidade, podemos entender aquilo que "me distancia da minha própria potência” (TIQQUN, 2019, p. 43). Aqui há uma ambivalência. $\mathrm{Na}$ mesma edição da revista tiqqun, tem-se a leitura de que a hostilidade pode ser praticada e acontecer de formas diversas, com resultados e métodos distintos: uma "relação mercantil ou contratual, a difamação, a violação, o insulto, a destruição pura e simples, colocam-se lado a lado: são práticas de redução"; e "outras formas de hostilidade tomam caminhos mais tortuosos e, por isso, menos aparentes", como a "polidez, a prudência, a hospitalidade, que se reconhecem mais raramente como práticas de achatamento" (TIQQUN, 2019, p. 40). Na "glosa" sobre a noção de hostil, a revista indica que mesmo o Vocabulário das instituiçoes indo-europeias, de Benveniste, não há uma explicação como, em latim, hostis pôde significar "estrangeiro', 'inimigo', 'anfitrião" (TIQQUN, 2019, p. 40). Há um duplo sentido que está posto e relaciona-se à esfera da amizade e da inimizade como noções ético-políticas.

Quando falo de uma "comunidade que vem", tenho no imaginário essas circulações de afetos. O que há de uma comunidade que vem é vivenciado como acontecimento e elevação de um tempo ordinário - são rastros de graça (kairós). Uma comunidade como "ressonância" nas casas/redes/ruas na quarentena, em que nas "rachaduras" da carne podemos inventar "magias participáveis", uma zona nebulosa e indeterminável entre esses corpos e suas relações ambivalentes de hospitalidade e hostilidade. Há acontecimentos em que esses agenciamentos podem ser sentidos de maneira mais latentes, como as mobilizações políticas antirracistas e antifascistas promovidas pelas torcidas organizadas na Avenida Paulista (São Paulo), o bloqueio da utilização dos aplicativos de entrega, as "conexões" entre janelas para os gestos de protestos em relação ao presidente Jair Bolsonaro. As relações de trabalho precárias e desiguais, ao lado da evidência das relações raciais perversas e dos projetos e programas totalitários no contexto brasileiro empurram os corpos para espaços provisórios de tensão e imaginação política, sem se deixarem enclausurar na ilusão do um $^{12}$. A estranheza é esta. Como ter algo de

12 Para uma análise sobre a ampliação das desigualdades no cenário da pandemia, confira dois textos produzidos pelo "Instituto Tricontinental de Pesquisa Social" a partir da pesquisa das "Juventudes em Periferias Urbanas". O primeiro é esse: "Periferias e pandemia: desigualdades, resistências e solidariedade"(Disponível: https://url.gratis/dBirR); o segundo: "Efeitos sociais da pandemia no trabalho e renda entre os mais pobres" (Disponível: https://url.gratis/FhfbK). 
comunidade sem o pertencimento do "povo", sem os "programas" e projetos de unidade e sentido? Não seria aqui se aventurar na própria experiência da "paixão ingovernável"? Ou deixar-se arrastar pela energia da graça e poder erótico para além da biopolítica da sobrevida? Como construir modos de vida, o viver junto, jogando e destituindo "identidades"? Como ser "cristo uma para as outras", em que o ser cristo é vazio e, por isso, um espaço de ocupação e habitação das inclinações de outros corpos, em suas próprias fraquezas (vida nua) - como símbolo de abandono e de potência?

Giorgio Agamben nos ajuda nesse momento em sua entrevista sobre Uma biopolitica menor. Ele foi indagado desse modo: "no seu entendimento, a nova biopolítica, essa política que se anuncia, revela mais sobre a fuga ou a saída do que sobre a resistência ou o conflito" (AGAMBEN, 2016, p. 18). A pergunta que decorre daí é inquietante: "como se desprender de si, se esquivar da ressubjetivação, ser um não estado etc, quando se é “soropositivo', 'desempregado' ou 'toxicômico', isto é, preso, literalmente, nas categorias e dispositivos de poder?" (2016, p. 19). Aqui está um ponto decisivo na crítica a Agamben e - de algum modo - nas possíveis suspeitas com a leitura que faço nesse artigo. Como falarmos em desaparecimento do humano ou da comunidade se pensarmos nos corpos vistos como "sub-humanos"? A resposta de Giorgio Agamben apresenta uma problematização daquilo que seja a "fuga". A sua perspectiva é imaginar uma fuga que não significa evasão, mas "um movimento na situação em que ele acontece" (2016, p. 20). Para aprofundar sua interpretação, ele se aproxima da crítica de Marx a Stirner em $A$ ideologia alemã, especialmente na distinção entre revolta e revolução. Em síntese, segundo nosso filósofo, Marx propõe uma unidade entre essas duas noções, não opondo um "conceito político" a um "conceito anárquicoindividual". Nesse sentido, afirma Agamben:

tenderia a pensar não em um corte que isola fuga da revolução, como é um tendência a se fazer, mas que todo ato que emana da necessidade singular de um individuo, do proletário, que não tem nenhuma identidade, nenhuma substância, será também, apesar de tudo, um ato político (AGAMBEN, 2016, p. 21)

Se a identidade e o se fazer sujeito colocam uma sujeição sobre o corpo diante de uma "biopolítica da sobrevivência" (como indicado na pergunta), a energia e potência estão justamente em assumir a "forma-de-vida" que é possível nessa vida nua capturável no espaço da quarentena tecnomediada. É o exercício do jogo como uma possibilidade de não se deixar reduzir - 
um agir politicamente - ao "povo", à "identidade", à "comunidade como pertencimento", uma "necessidade singular", ao "trabalhador flex-digital'. Há algo que vaza e desorganiza, que irrompe por meio de uma dessubjetivação. Por isso, o problema em indicar a "identidade" - de um sujeito, de um deus - como o ponto de partida necessário para a "resistência e o conflito" dentro de um horizonte de hegemonia provocada em uma "racionalidade neoliberal".

Como exemplo, eu me interesso por Silvia Rivera Cusicanqui. Em uma entrevista com essa autora boliviana, Veronica Gago escreve: "Rivera Cusicanqui tem uma arte, e é escapar das classificações, especialmente de lugares exóticos onde querem localizá-la. Ela diz que é por isso que muitas vezes pensam que ela é uma antropóloga. Ela ri e se chama de "objeto étnico não identificado” (CUSICANQUI, 2016). Quando a querem colocála na sujeição da identidade, há várias fugas e necessidades singulares que empurram o corpo para viver de outros modos. Por exemplo, "às vezes ela também se refere a si mesma como uma sochóloga, uma mistura de chola e socióloga, algo que uma vez lhe foi dito para desacreditá-la, e ela converteu esse nome em uma bandeira" (2016). Todos esses gestos de Cusicanqui "são os lampejos de um sorriso mais profundo e uma crítica radical sobre a essencialização dos indígenas” (2016). Há algo cômico em destituir esses modelos de clausura, uma festa em destituir a segurança identitária. A pergunta feita a Agamben - com base naqueles corpos "presos, literalmente, nas categorias e dispositivos de poder" - tem uma intuição interessante, mas no fundo essa indagação tenta colocar a todos nós em um esquema que, por exemplo, Cusicanqui deseja abandonar o essencialismo e a impossibilidade de "fuga" dos dispositivos de poder e de identidade e de preservação. Não poderíamos assumir o vazio da queda: política, subjetiva-existencial, comunitária e simbólico-teológica? Não estaríamos, aqui, diante de novas possibilidades afetivas e ficcionais para novas "formas-de-vida" virtuais em instantes provisórios de encontros, desencontro, cuidado e afastamento?

\section{v. Considerações finais}

Encerro esse artigo retomando a obra de Ananda Trezena (2020): "enquanto isso tudo não acaba". Sem o saudosismo de um passado comunitário; sem a clausura no ideal de progresso tecnológico trans-humano, como viver junto e só na quarentena antes que esse tempo se encerre? Como assumir o tempo sem se deixar reduzir às saídas teológicas de uma teodiceia em que a pandemia sinaliza o mal explicado por uma divindade? O exercício 
teórico-imaginativo desse artigo parte desses problemas. Estamos diante do "tempo-agora" e é preciso encontrarmos nele brechas, fissuras e rachaduras vistas no corpo e nas relações. Essa perspectiva passa por detrs, pelas visões e construções que temos dessa palavra-com-poder. É fazer conjunções entre "corpos inclinados" e virtuais e a partir daqui ensaiar novas linguagens mítico-teológicas, que passam pelo esvaziamento de uma ideia de trindade, de uma ideia de humano, de uma noção de comunidade-povo. Como provoca o Laboratório Zona de Contágio ao construir o seu horizonte:

Não uma recusa técnica, mas uma tecnopolítica que sustente formas de existência não-fascistas, não-binárias, emaranhadas. Como pensar a corrosão democrática a partir da aposta na disputa dos regimes de conhecimento as disputas em relação à ciência, os saberes menores e não autorizados, as ontoepistemologias dos saberes das lutas que possam reconfigurar nossas arquiteturas e espaços de conhecimento? Como escapar das escolhas infernais? (LZC, 2020b).

É viver no "tempo-agora" e "passar". Uma estratégia mítica de desertar, sair. Neste cenário, me recordo da Carta aos amigos do deserto, escrita por Marcello Tarì. Em um dos trechos, relacionando o deserto com a "ausência de palavras", ele afirma: em hebraico, "o termo que descreve "palavra", dabar, e o que descreve "deserto", midbar, têm a mesma raiz, o que nos permite supor que o facto do deserto ser privado de palavra, e precisamente por isso, torna-o o sítio adequado para a revelação da Palavra enquanto evento" (TARÌ, 2020). A palavra como um acontecimento. E também a possibilidade criadora de novos mundos e nova vida, mesmo quando a incerteza é a morada mais profunda. Não é esse o mito fundante de Gênesis, um mundo que do nada acontece por meio da palavra dita? Saber viver no silêncio, saber habitar a palavra para enunciar novos arranjos de vida comunitária, "antes que tudo isso acabe". Ensaiar desde um corpo desértico o abandono de um modo de vida focado no desempenho ou numa comunidade da clausura e segurança em um “povo". Sair. Como escreve novamente Marcello Tarí: "o deserto foi onde se reuniram os primeiros monachoi, os 'solitários', aqueles que se afastaram dum império de decadência e injustiça”" (TARÌ, 2020). Talvez, aqui, assumindo-se nesse espaço, encontraremos saídas para, provocados por novas estéticas da existência, construirmos redes, vinculações, camaradagens e outros modos para respirar e dizer/praticar mundos. 


\section{O vazio e a "comunidade que vem": \\ reflexões político-teológicas desde a pandemia da COVID-19}

\section{Referências}

AGAMBEN, Giorgio. A comunidade que vem. Belo Horizonte: Autêntica Editora, [1990] 2013.

Teología y lenguaje: del poder de Dios al juego de los niños. Buenos Aires (Argentina): Editora Las cuarenta, [2012] 2012.

. Uma biopolítica menor. Coleção Pandemia. São Paulo: Editora n-1, [2000] 2016.

BERARDI, Franco Bifo. Crônica da psicodeflação. N-1 edições. 2020. Acesso em 01 de abril de 2020 .

BUBER, Martin. Sobre comunidade. São Paulo: Editora Perspectiva, 2012.

CUSICANQUI, Silvia. Contra el colonialismo interno. 2016. Revista Anfíbia. Disponível: https://bit.ly/2HSyG5X.

DARDOT, Pierre \& LAVAL, Christian. A nova razão do mundo: ensaio sobre a sociedade neoliberal. São Paulo: Boitempo, 2016.

DICKINSON, Colby. Agamben and teology. New York (Estados Unidos): t\&t clark, 2011.

ESTER, Ana. Teologia Biônica - contágios pós-humanos decoloniais. Série Contágios Infernais. São Paulo: Editora Recriar, 2020. Disponível: https://url.gratis/Xse85. Acesso: 25 de julho de 2020.

FLUSSER, Vilém. Língua e realidade. São Paulo: Annablume, 2007.

GEBARA, Ivone. Mulheres, religião e poder: ensaios feministas. São Paulo: Edições Terceira Via, 2017.

_. Trindade. Palavras sobre coisas velhas e novas. Uma perspectiva Ecofeminista. Paulinas: São Paulo: 1994.

HAN, Byung-Chul. Sociedade do cansaço. Petrópolis: Editora Vozes, 2017 a.

INSTITUTO TRICONTINENTAL. Periferias e pandemia: desigualdades, resistências e solidariedade. Disponível: https://url.gratis/dBirR. Acesso em 26 de julho de 2020.

Efeitos sociais da pandemia no trabalho e renda entre os mais pobres.

Disponível: https://url.gratis/FhfbK. Acesso em 26 de julho de 2020.

KRENAK, Ailton. Ideias para adiar o fim do mundo. São Paulo: Companhia das letras, 2019.

LAB ZONA DE CONTÁGIO. Respirar: uma ciência dos contagiosamente vivos. 2020a. Disponível: https://url.gratis/Occ0W. Acesso em 25 de julho de 2020.

Inventar brechas, suturar os controles, educação, crise da presença e imaginações teconopolíticas. 2020b. Disponível: https://url.gratis/fuibS. Acesso em 25 de julho de 2020.

MOLTMANN, Jürgen. Vida, esperança e justiça: um testamento teológico para a América Latina. São Bernardo do Campo: Editeo, 2008. 
PELBART, Peter Pál. Como viver só. Em: BIENAL DE SÃO PAULO. $27^{\mathrm{a}}$ Bienal de São Paulo: Seminários. Rio de Janeiro: Cobogó, 2008, p. 267-275.

PONTE JORNALISMO. Fomos punidos por greve, denuncia entregador. Disponível: https://url.gratis/xpCtk. Acesso em 25 de julho de 2020.

PRECIADO, Paul B. A conspiração dos perdedores. Medium - Sara Wagner. 2020. Acesso em 01 de abril de 2020a.

Aprendiendo del vírus. El País. 2020b. Acesso em 01 de abril de 2020.

RIEGER, Joerg. Graça sob pressão: negociando o coração das tradições metodistas. São Bernardo do Campo: Editeo, 2012.

RIVITTI, Thais. Clínica geral - quem somos (e para onde vamos). Exposição 397flix. Disponível em: https://url.gratis/Ma2fF. Acesso em 26 de julho de 2020.

SOUZA, Daniel Santos. A "revolta da ineficiência": os acontecimentos de junho de 2013 no Brasil e suas destituições político-teológicas. Tese de doutorado em Ciências da Religião. Escola de Comunicação, Educação e Humanidades. Programa de Pós-Graduação em Ciências da Religião da Universidade Metodista de São Paulo (UMESP). São Bernardo do Campo, 2019. 349p.

Cristologia na encruzilhada: possibilidades de uma cristologia pluralista da libertação a partir de J. Dupuis e J. Sobrino. São Paulo: Editora Reflexão, 2016. . a redenção do silêncio. Revista Senso. Disponível em: https://url.gratis/icjCP.

TARÌ, Marcello. Carta aos amigos do deserto. Disponível em: https://url.gratis/Ot18k. Acesso em 26 de julho de 2020.

TIQQUN. A contribuição para a guerra em curso. São Paulo: edições n-1, 2019.

TOMITA, Luiza. "Crista na ciranda de Asherah, Isis e Sofia: propondo metáforas divinas para um debate feminista do pluralismo religioso". In: ASETT (org.). In: Pluralismo e libertação: por uma Teologia Latino-Americana Pluralista a partir da fé cristã. São Paulo: Loyola, 2005, pp. 107-124.

TREZENA, Ananda. enquanto isso tudo não acaba. Exposição 397flix. Disponível em: https://url.gratis/4F2ve. Acesso em 26 de julho de 2020.

ZUBEN, Newton A. von. Posfácio. Em: BUBER, Martin. Sobre comunidade. São Paulo: Editora Perspectiva, 2012.

Submetido em: 10-2-2021

Aceito em: 19-5-2021 